\title{
Detection of the Change in Blogger Sentiment using Multivariate Control Charts
}

\author{
Jeounghoon Moon $^{a} \cdot$ Sungim Lee ${ }^{b, 1}$ \\ ${ }^{a}$ BigAnalytics, Information Strategy Department, ElandSystems Ltd. \\ ${ }^{b}$ Department of Statistics, Dankook University
}

(Received July 17, 2013; Revised September 6, 2013; Accepted October 29, 2013)

\begin{abstract}
Social network services generate a considerable amount of social data every day on personal feelings or thoughts. This social data provides changing patterns of information production and consumption but are also a tool that reflects social phenomenon. We analyze negative emotional words from daily blogs to detect the change in blooger sentiment using multivariate control charts. We used the all the blogs produced between 1 January 2008 and 31 December 2009. Hotelling's T-square control chart control chart is commonly used to monitor multivariate quality characteristics; however, it assumes that quality characteristics follow multivariate normal distribution. The performance of a multivariate control chart is affected by this assumption; consequently, we introduce the support vector data description and its extension (K-control chart) suggested by Sun and Tsung (2003) and they are applied to detect the chage in blogger sentiment.
\end{abstract}

Keywords: Multivariate control chart, support vector data description, K-chart.

\section{1. 서론}

\section{1. 연구 배경}

최근 소셜 네트워크 서비스(Social Network Service; SNS) 등 소셜 미디어(social media)의 발달로 하 루에도 수백만 건의 글들이 SNS를 통해 얻어지고 있으며, 이러한 글들은 사용자 개개인의 심리상태나 감정 또는 경험들을 반영한다. 소셜 미디어는 웹(Web) 기술의 발전과 네트워크의 고속화, 그리고 스마 트폰 등 다양한 정보기기의 확산으로 소셜 네트워크 서비스를 지원하는 고도의 어플리케이션이다. 이러 한 소셜 미디어는 온라인 이해집단의 사회적 영향력을 증대시켰고 미래 사회 발전을 위한 전략적 대안으 로 자리 잡고 있다 $(\mathrm{Oh}, 2010)$. 기존의 미디어가 대중매체(mass media)와 같이 방송사나 잡지사 또는 신문사와 같은 일방적인 정보 및 사실을 전달하는 것이었다면, 소셜 미디어는 개인의 의견에 또 다른 생 각을 더하는 등의 참여가 가능해지면서 누구나 정보를 생산하고 소비하는 것이 가능해졌다. 따라서 사 회적 이슈나 사건들이 개개인에게 영향을 주게 되며, $\mathrm{SNS}$ 를 통한 자기감정의 표현은 또 다른 사람에게

This research was supported by the Basic Science Research Program through the National Research Foundation of Korea(NRF) funded by the Ministry of Education, Science and Technology(2011-0025168).

${ }^{1}$ Corresponding author: Associate Professor, Department of Statistics, Dankook University, 152, Jukjeon-ro, Suji-gu, Yongin-si, Gyeonggi-do 448-701, Korea. E-mail: silee@dankook.ac.kr 
전달되어 급속한 확산으로 인한 파급효과가 기하급수적으로 커지게 된다. 그러므로 사회현상을 잘 반영 하는 SNS 문서를 분석하는 것은 사회의 불안정성을 인식할 수 있는 중요한 관리도구가 될 것이며, 본 연구에서는 이러한 문서의 특성을 분석하는 과정에서 품질관리에서 많이 사용되는 통계적 공정관리기법 을 적용해 보고자 한다.

통계적 공정관리의 중요한 목적 중의 하나는 공정의 이상을 조기에 발견하고 그 원인을 파악하여 공정 을 안정화 시키는 것이다. 이러한 목적으로 사용되는 대표되는 기법이 관리도인데, 관리도는 Shewhart (1931)의 $\bar{X}$ 관리도로부터 시작되어 계속된 연구와 발전을 거듭하였다. 그러나 최근에는 컴퓨터의 발 달 등으로 인하여 수많은 품질 특성치들을 관측할 수 있게 되면서 품질 특성치들간 상호 연관성 등의 문 제로 인하여 기존의 일변량 관리도(univariate statistical process control; SPC)를 통한 관리가 어렵 게 되었다. 이렇듯 상호 연관성이 존재하는 품질 특성치들에 대하여 일변량 관리도를 통해 관리하는 것 은 올바르지 않으며, 따라서 이러한 특성치를 동시에 관리하는 다변량 관리도(multivariate statistical process control)의 중요성이 점점 더 강조되고 있다 (Montgomery, 2001). 이러한 다변량 관리도에는 Shewhart 형태의 호텔링 $T^{2}$ 관리도 (Hotelling, 1931)와 다변량 CUSUM 관리도 (Crosier, 1988), 다 변량 EWMA 관리도 (Lowry 등, 1992; Prabhu와 Runger, 1997) 등이 있다. 호텔링의 $T^{2}$ 관리도는 가장 널리 사용되는 관리도 중 하나로서, 현재 시점의 관측치에 근거하여 관리통계량을 계산한 후 공정 의 이상 유무를 판단하는 관리도로 데이터의 공정관리 초기에 적합한 관리도이다. CUSUM 관리도와 $\mathrm{EWMA}$ 관리도는 공정관리를 통해 공정이 어느 정도 안정된 후 공정의 작은 변화를 빠르게 탐지하도 록 과거의 데이터와 현재 시점에서 얻어진 값을 누적하여 관리통계량으로 사용하는 것이다 (Chiang 등, 2001; Montgomery, 2001). 그러나 위에서 언급한 여러 관리도는 관측치들이 독립이고, 정규분포를 따 른다는 가정이 필요하다. 하지만 본 연구에서 관심 있는 트위터나 블로그 등을 통하여 얻는 데이터의 경 우 일반적으로 확률 분포를 알기가 어려우며 정확하게 추정하는 것 또한 쉽지가 않다.

\section{2. 연구 목적}

소셜 미디어의 발달로 인하여 사용자들은 자신의 감정을 $\mathrm{SNS}$ 를 통해서 직접적으로 표현하고 있다. 따 라서 SNS 사용자들이 표현하는 감성어에 대한 데이터 분석을 통해 그들의 정서를 파악할 수 있으며, 최 근에는 이러한 소셜 미디어 자료에 대한 분석이 활발하게 이루어지고 있다. Kramer (2010)는 대표적인 $\mathrm{SNS}$ 중 하나인 페이스북에서의 사용자들 감성어들을 통하여 GNH(Gross National Happiness) 지수를 제안하였다. GNH 지수는 긍정 감성어와 부정 감성어의 사용 빈도수에 대한 평균 차이를 통해 계산되 며, 이를 통해 사회의 행복 정도를 제시하였다. 또한 Hong (2011)은 SNS 상에서의 담론 분석을 통하여 인지적, 정서적 측면에서의 여론 변화에 대한 연구를 실시하였는데, 트위터에서 일정기간동안 수족구 질 병에 대하여 자주 등장하는 감성어들에 대하여 시간의 변화에 따라 이들 감성어들에 대한 각각의 빈도수 를 제시함으로써 이를 바탕으로 여론 변화 시점을 파악하고자 하였다.

본 연구에서는 블로그에 자주 사용되는 부정적인 감성어들에 대하여 이들을 사용한 블로거들의 전체 수 를 일별로 관측하여 블로거들의 정서가 변화하는 시점을 탐지하고자 한다. 앞서 언급한대로 부정적인 감성어들(예를 들어, "힘들다", "외롭다", "죽고싶다" 등)에 대하여 각각의 감성어를 사용한 전체 블로 거들의 수는 상호 연관성이 존재하게 되고, 이러한 감성어들에 대한 빈도수는 다변량 데이터를 형성하게 된다. 기존 연구에서는 단지 긍정적이거나 부정적인 단어의 빈도수 사이의 차이라던지 혹은 개별적인 단어에 대한 빈도수만 고려한 반면에, 이번 연구에서는 다변량 데이터를 활용하여 공정의 이상요인 발생 을 탐지하는 데 사용되는 다변량 관리도기법을 적용하여, 이상 요인이 발생하는 시점과 당시 발생한 사 회적 사건가 일치하는 것을 보이고, 소셜 미디어 데이터에 대해서도 관리도 기법을 적용해서 사회의 부 정적 정서 변화를 탐지하는 데 적용 가능함을 보이고자 한다. 


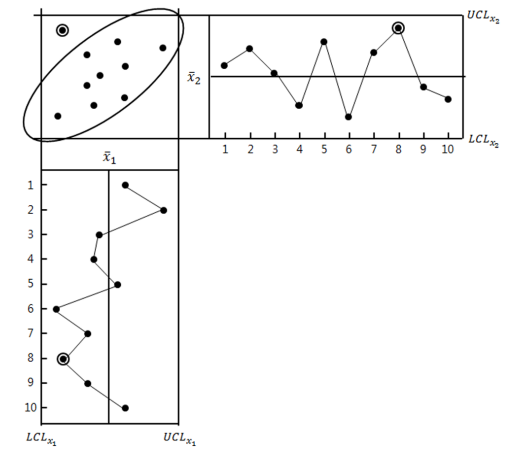

Figure 2.1. Univariate and multivariate control charts

다변량 관리도기법으로는 호텔링의 $T^{2}$ 관리도 등이 자주 사용되는데, 실제 문제에서의 다변량 자료는 대부분 정규분포를 따르지 않기 때문에 사용에 많은 제약이 존재한다. 반면에 서포트 벡터를 이용한 Support Vector Data Description(SVDD) (Tax와 Duin, 2004)과 서포트 벡터에 근거한 K-관리도 (Sun과 Tsung, 2003)는 이러한 확률가정이 필요 없고, 실제문제에 더 좋은 성능을 보여준다고 알려져 있다 (Sukchotrat 등, 2010; Gani 등, 2011). 이에 본 연구에서는 2절에서 SVDD와 K-관리도를 소개하 고, 3 절에서는 소셜 미디어 자료를 적용해 보고자 한다. 마지막으로 4 절에서는 결론 및 향후과제에 대 하여 다루도록 하겠다.

\section{2. 서포트 벡터 기반의 다변량 관리도}

통계적 공정관리에서 관리도를 이용하는 중요한 목적은 공정의 이상을 탐지하여 그 원인을 파악하고 수 정함으로써 불량 제품의 발생을 사전에 억제하여 공정의 산포를 효율적으로 관리하는 것이다. 관리도 는 품질 특성치의 개수에 따라서 단변량 관리도와 다변량 관리도로 나누어진다. 단변량 관리도는 하나 의 품질 특성치를 관리하고자 할 때의 관리도이다. 반면 품질 특성치가 2 개 이상의 다변량으로 주어지 는 경우, 이를 동시에 모니터링을 하기 위해서는 다변량 관리도가 필요하다. 다변량 관리도는 단변량 관 리도가 찾아내지 못하는 이상 징후를 파악할 수 있는데, Figure 2.1과 같이 상관관계가 있는 두 특성치 들을 모니터링할 때 이들의 상관관계를 고려하여 이상 유무를 파악할 수 있기 때문이다.

이처럼 다변량 관리도의 주요 목적은 데이터의 이상 상태를 탐지하기 위한 것이고 이를 위해서는 적절 한 관리 한계선(control limits)을 설정하는 것이 매우 중요하다. 그런데 관리 한계선의 설정은 앞에서 도 언급한 바와같이 데이터의 확률분포가정에 의존하게 되는데, 실제 문제에서는 확률 분포가 알려져 있 지 않거나 정규분포를 가정하기 어려운 경우를 자주 접하게 된다. 이에 블로거들의 부정적인 감성어 사 용에 대한 변화를 탐지하기 위한 관리도의 관리한계선을 정하는 문제를 단일 클래스 분류문제로 접근하 고, 서포트 벡터를 이용한 SVDD를 적용하거나 SVDD 알고리즘을 기초로 커널거리를 사용한 $\mathrm{K}$-관리 도 (Sun과 Tsung, 2003)를 적용하기 위해 이들에 대해 알아보기로 한다.

\section{1. 서포트 벡터 데이터 표현(Support Vector Data Description; SVDD)}

Tax와 Duin (2004)이 제안한 SVDD는 비선형 SVM(Support Vector Machine)을 단일 집단(OneClass Classification)의 분류에 사용한 것인데, $\mathrm{SVDD}$ 의 주요 아이디어는 고차원 공간의 자료를 가능 한 한 적은 부피를 갖는 초구면(hypersphere)으로 포함하는 것이다. 이때 초구면은 Figure 2.2와 같이 


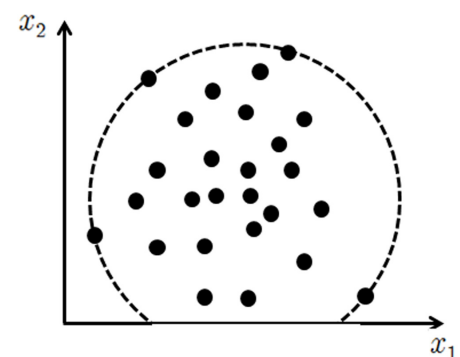

Figure 2.2. SVDD hyperplane of two-dimensional space

데이터를 둘러싸는 경계를 나타낸다.

즉, 데이터가 2 차원인 경우 초구면은 곧 원이 되며, 공정이 정상 상태일때 $p$ 개 변수를 갖는 데이터 $\mathbf{x}=$ $\left(x_{1}, x_{2}, \ldots, x_{p}\right)^{\prime}$ 에 대하여 $n$ 개의 정상 데이터 $\mathbf{x}_{1}, \mathbf{x}_{2}, \ldots, \mathbf{x}_{n}$ 를 이들에 대한 초구면을 구한다면 이것은 데이터의 정상 상태와 이상 상태를 나타내는 관리한계선을 의미하게 된다. 이때 관리한계선은 정상태이 터를 모두 포함하면서 초구면의 부피를 최소화하도록 초구면의 중심 $O$ 와 반경 $R$ 은 다음을 만족하도록 결정된다.

$$
\left\|\mathbf{x}_{i}-\mathbf{O}\right\|^{2} \leq R^{2}, \quad \text { for any } i=1,2, \ldots, n,
$$

여기서 초구면의 중심 $O$ 와 반경 $R$ 은 다음의 라그랑지 함수를 통해 최적화 될 수 있다.

$$
L=R^{2}-\sum_{i=1}^{n} \alpha_{i}\left\{R^{2}-\left\|\mathbf{x}_{i}-\mathbf{O}\right\|^{2}\right\}, \quad \alpha_{i} \geq 0 .
$$

위의 식을 $R$ 과 $O$ 에 대해 편미분하면 다음과 같이 두 개의 식이 만들어진다.

$$
\sum_{i=1}^{n} \alpha_{i}=1, \quad \mathbf{O}=\sum_{i=1}^{n} \alpha_{i} \mathbf{x}_{i}, \quad \text { for any } i=1,2, \ldots, n .
$$

이 결과 식 $(2.2)$ 는 다음과 같이 다시 쓸 수 있다.

$$
L=\sum_{i=1}^{n} \alpha_{i}\left(\mathbf{x}_{i} \cdot \mathbf{x}_{i}\right)-\sum_{i, j=1}^{n} \alpha_{i} \alpha_{j}\left(\mathbf{x}_{i} \cdot \mathbf{x}_{j}\right)
$$

이 때, $\left(\mathbf{x}_{i} \cdot \mathbf{x}_{j}\right)=\sum_{k=1}^{n} x_{i k} x_{i k}$ 로 두 벡터의 내적을 의미한다. 식 (2.3)의 제약식이 있을 때 위의 식을 최소화하는 것은 $\mathrm{QP}\left(\mathrm{Quadratic}\right.$ Programming) 문제로 식 $(2.3)$ 에 대한 최적해 $\alpha_{i}(i=1, \ldots, n)$ 를 구 하는 알고리즘이 잘 알려져 있다. 대부분의 값은 0 과 같고, 극히 일부분이 0 보다 크게 나타나는데, 이에 해당하는 $\alpha_{i}$ 를 초구면을 이루는 서포트 벡터라고 부른다. Figure 2.2 에서 살펴 보면 원 위에 있는 4 개 의 점이 서포트 벡터를 나타낸다. 새로운 관측치로 $(\mathbf{z})$ 부터 초평면의 중심 $(\mathbf{O})$ 까지의 거리는 모니터링에 서 유용하게 사용될 수 있는데, 즉 이 거리가 크다면 관리도에서 이상 상태일 가능성이 더 크다고 할 수 있다. 즉,

$$
D=\|\mathbf{z}-\mathbf{O}\|
$$

을 계산하여, 거리 $(D)$ 가 반경 $(R)$ 보다 크다면, 관측치는 이상 상태로 분류된다. 또, 중심 $O$ 대신에 식 

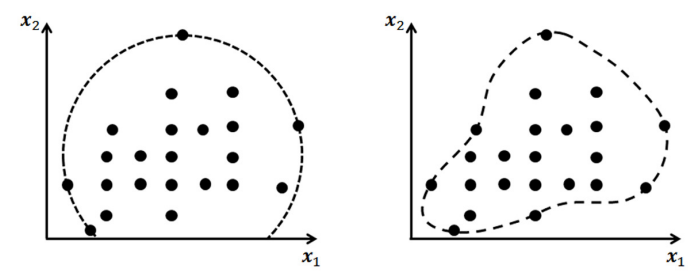

Figure 2.3. Comparison of two types of boundary. hyperplane(left), SV(right)

(2.3)의 추정식을 사용한다면 거리 $(D)$ 는 다음과 같이 쓸 수 있다.

$$
D=\sqrt{(\mathbf{z} \cdot \mathbf{z})-2 \sum_{i=1}^{n} \alpha_{i}\left(\mathbf{z} \cdot \mathbf{x}_{i}\right)+\sum_{i, j=1}^{n} \alpha_{i} \alpha_{j}\left(\mathbf{x}_{i} \cdot \mathbf{x}_{j}\right)} .
$$

\section{2. $\mathrm{K}$-관리도(K-Chart)}

데이터의 모양이 초구면이 아닌 경우 $\mathrm{SVDD}$ 를 이용해 데이터를 둘러싸는 경계를 찾게된다면 그 경계 가 다소 넓어지는 경향이 있다. 따라서 데이터의 공간 $(x)$ 을 새로운 특성 공간 $(\Phi(x))$ 으로 옮겨서 Figure 2.3 의 오른쪽과 같이 데이터를 둘러싸는 좀 더 엄격한 경계를 찾고 이를 활용한 관리도가 $\mathrm{K}$-관리도이다. 즉, 식 (2.1)에서 데이터 $\mathbf{x}$ 대신 이를 특성 공간으로 옮긴 $\Phi(\mathbf{x})$ 로부터 다음을 만족하는 $O$ 와 $R$ 을 구하 도록 한다:

$$
\left.\| \Phi\left(\mathbf{x}_{i}\right)-\mathbf{O}\right) \|^{2} \leq R^{2}, \quad i=1,2, \ldots, n .
$$

이것은 2.1 절에서와 유사하게 식 (2.4)에서 $\mathbf{x}$ 의 내적을 커널 함수 $K\left(\mathbf{x}_{i} \cdot \mathbf{x}_{j}\right)=\Phi\left(\mathbf{x}_{i}\right) \cdot \Phi\left(\mathbf{x}_{j}\right)$ 로 대체하 는 것으로 구할 수 있다 (Sun과 Tsung, 2003).

$$
L=\sum_{i=1}^{n} \alpha_{i} K\left(\mathbf{x}_{\mathbf{i}} \cdot \mathbf{x}_{\mathbf{i}}\right)-\sum_{i, j=1}^{n} \alpha_{i} \alpha_{j} K\left(\mathbf{x}_{\mathbf{i}} \cdot \mathbf{x}_{\mathbf{j}}\right)
$$

여기서도 $\mathrm{QP}$ 프로그래밍을 통해 $\alpha_{i}$ 를 구할 수 있으며, 이들 중 양의 값을 가지는 $\alpha_{i}$ 가 서포트 벡터를 구성한다. 새로운 관측치와 서포트 벡터의 거리 또한 식 (2.4)의 내적을 커널 함수로 대체한 아래의 식 과 같으며, 이를 통해 커널 거리(kernel distance)를 얻을 수 있다.

$$
\mathrm{KD}=\sqrt{K(\mathbf{z} \cdot \mathbf{z})-2 \sum_{i=1}^{n} \alpha_{i} K\left(\mathbf{z} \cdot \mathbf{x}_{\mathbf{i}}\right)+\sum_{i, j=1}^{n} \alpha_{i} \alpha_{j} K\left(\mathbf{x}_{\mathbf{i}} \cdot \mathbf{x}_{\mathbf{j}}\right)} .
$$

이로부터 $\mathrm{KD} \leq R$ 이면 정상상태, $\mathrm{KD}>R$ 이면 이상상태로 이해할 수 있다. 본 논문의 자료 분석에서 는 커널함수 $K(\cdot)$ 로 다음의 두 함수를 사용할 것이다.

- 가우시안 원형기반함수(Gaussian Radial Basis Function)

$$
K\left(\mathbf{x}_{i} \cdot \mathbf{x}_{j}\right)=\exp \left(-\frac{\left\|\mathbf{x}_{i}-\mathbf{x}_{j}\right\|^{2}}{\sigma^{2}}\right), \quad \sigma>0 .
$$

- 다항함수(Polynomial function)

$$
K\left(\mathbf{x}_{\mathbf{i}} \cdot \mathbf{x}_{\mathbf{j}}\right)=\left(\mathbf{x}_{\mathbf{i}} \cdot \mathbf{x}_{\mathbf{j}}\right)^{d}, \quad d \in\{1,2, \ldots\} .
$$


Table 3.1. Descriptive statistics for daily number of bloggers using each word per every hundred thousand bloggers during 2008 and 2009 .

\begin{tabular}{crrrrrrr}
\hline & \multirow{2}{*}{ Mean } & Standard deviation & Min & Max & \multicolumn{3}{c}{ Quantile } \\
\cline { 6 - 8 } & & & & 25 & 50 & 75 \\
\hline 힘들다 & 2806.24 & 181.45 & 2289.10 & 3611.80 & 2684.30 & 2806.90 & 2926.70 \\
아프다 & 1679.61 & 160.57 & 1364.30 & 2324.40 & 1556.60 & 1673.60 & 1777.70 \\
안타깝다 & 396.31 & 85.52 & 288.50 & 1393.20 & 357.30 & 381.20 & 407.90 \\
외롭다 & 335.07 & 48.09 & 213.00 & 538.20 & 299.80 & 335.20 & 365.20 \\
괴롭다 & 212.44 & 35.18 & 142.70 & 541.30 & 186.80 & 209.20 & 231.60 \\
불쌍하다 & 156.76 & 26.96 & 103.40 & 341.30 & 137.20 & 154.80 & 171.40 \\
죽고싶다 & 48.54 & 12.69 & 22.40 & 166.50 & 40.60 & 47.00 & 54.30 \\
\hline
\end{tabular}

커널 함수로 다항함수를 선택할 때 $d=1$ 이면 이것은 곧 $\mathrm{SVDD}$ 와 같게 되어 데이터를 둘러싸는 경계가 초구면을 이루게 된다. $d>1$ 일때 데이터를 둘러싸는 경계가 좀 더 엄격하게 나타날 것이다.

\section{3. 실제 자료 분석}

\section{1. 자료 설명}

본 연구에서는 소셜 미디어 중 하나인 블로그를 통해 블로거들이 사용하는 부정적인 감성어들을 통하여 그들의 정서 변화를 탐지하기 위하여 다변량 관리도를 적용하고자 한다. 데이터는 (주)다음소프트에서 제공한 소셜 미디어 자료(Social Media Data)를 이용하였다. (주)다음소프트는 자연어처리기술을 통해 $\mathrm{SNS}$ 에서 발생하는 하루 수백만 건의 글을 자연어처리기술을 통해 글을 분석하고 분리하여 정제된 자료 를 제공한다. 본 논문에서는 하룻동안 블로그에 특정단어를 사용한 총 블로거 수를 데이터로 활용하였 다. 분석에 사용된 부정적인 감성어들은 “힘들다", “아프다”, "안타깝다”, "외롭다”, "괴롭다”, “불쌍하 다", 그리고 “죽고싶다”이며, 2008년 1월 1일부터 2009년 12월 31일까지 일별로 각 단어를 사용한 블로 그 문건수를 데이터로 분석하였다.

Table 3.1은 2008년 1월 1일부터 2009년 12월 31일 동안 각 감성어에 대하여 하루에 발생한 10 만건 당 특정 단어를 포함한 블로그 문건 수에 대한 기초통계량이다. “힘들다”의 표현은 하루 평균 10 만건 당 2806.24건의 블로그 문서가 발생하며, “아프다”의 표현은 10 만건당 1679.61 건, “안타깝다”의 표현 은 396.31건, "외롭다"의 표현은 335.07 건, "괴롭다"는 212.44 건, 불쌍하다의 표현은 156.76 건, “죽고싶 다"의 표현은 48.54 건의 블로그 문서수가 발생했다.

Figure 3.1은 7 개 감성어에 대한 사용 빈도수를 이용하여 전체 데이터의 특성을 살펴보기 위해 주성분 분석을 실시한 후 주요 주성분 두 개에 대하여 산점도를 나타낸 것이다. 여기에서 볼 수 있듯이 부정 적인 감성어들의 주성분을 살펴보면 대부분의 날이 비슷한 주성분을 나타내는데 비해 특정 날에는 주성 분이 매우 다르게 나타난다는 것을 볼 수 있다. 이러한 이상값이 발생하는 시점을 탐지하기 위하여 관 리도를 적용하였다. 이때, SVDD나 K-관리도에서 자료의 중심과 반지름을 구하기 위한 정상 자료로는 2008년 자료를 사용하고, 2009년 자료는 새로운 자료로 가정하였다.

\section{2. 관리도 적용}

위와 같이 정의된 자료를 바탕으로 다음과 같은 절차로 서포트 벡터 머신을 이용한 관리도를 적용해 보 았다. 먼저 Figure 3.2 는 2008 년도의 정상 자료를 이용하여 SVDD 관리도를 적용해 본 결과이다. 정상 자료에서 이상 상태에 있는 관측치를 고려하기 위하여, 정상 자료의 관측치들로부터 중심과의 거리를 구 


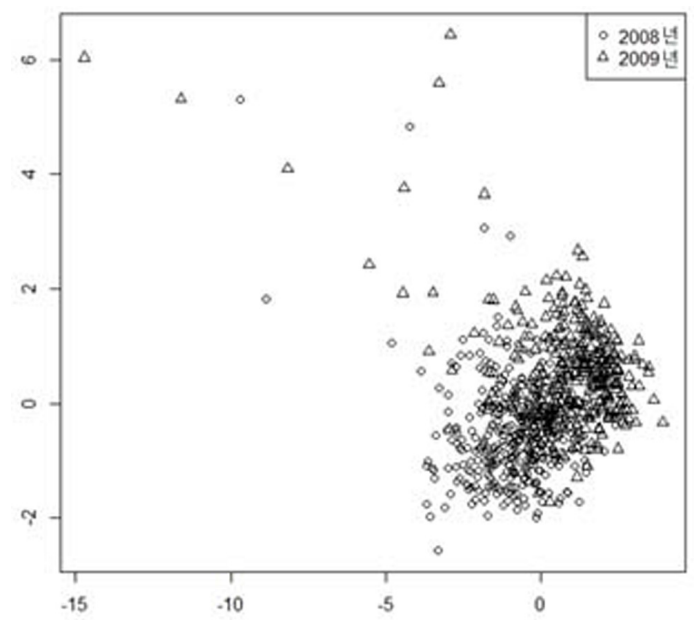

Figure 3.1. Annual score plot using Principal component analysis

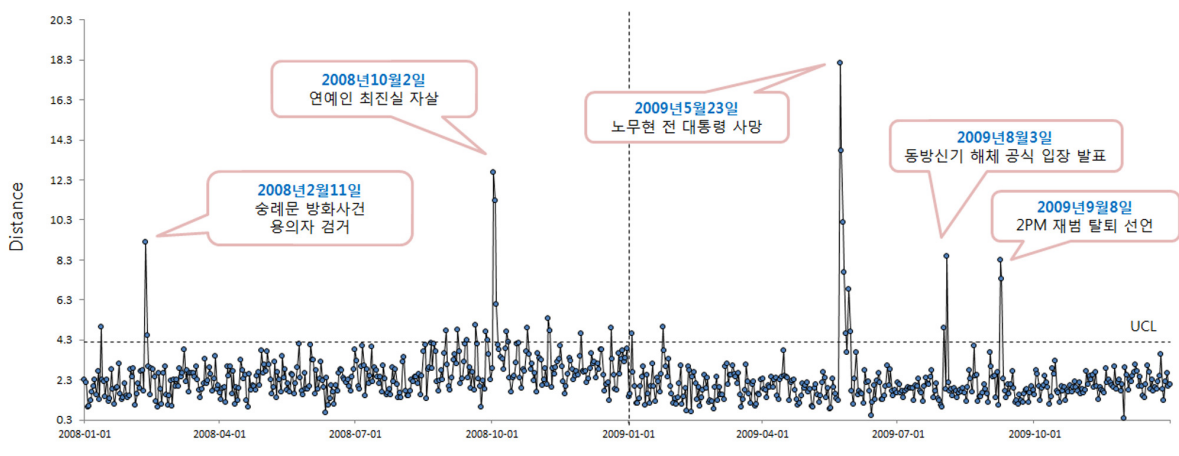

Figure 3.2. SVDD Control chart and the social issue and accidents of indicated dates

하고 이들 거리의 $95 \%$ 분위수를 반지름 $R$ 로 사용하였다. 이처럼 $\mathrm{SVDD}$ 관리도를 적용한 결과, 관리 상 한선은 4.1845로 나타났으며, 2008년과 2009년에 관리 상한선을 넘는 날이 있는 것을 알 수 있었으며, 또한 관리 상한선을 넘는 날에 사회적으로 민감한 이슈나 사건이 발생했던 것을 알 수 있었다.

다음 Figure 3.3 은 $d=2$ 인 다항 커널 함수를 이용하여 $\mathrm{K}$-관리도를 적용해 본 결과이다. 마찬가지로 관 리 상한은 정상 자료의 관측치들 거리의 $95 \%$ 분위수를 사용하였다. 이처럼 $\mathrm{K}$-관리도를 적용한 결과, 관 리 상한선은 17.3901로 나타났으며, 2008년과 2009년에 관리 상한선을 넘는 날이 있는 것을 알 수 있다. 다항 커널 함수의 K-관리도는 SVDD와 유사하므로 사회적 이슈와의 연결은 생략하기로 하겠다.

마지막으로 Figure 3.3은 커널 함수로 가우시안 원형기반함수를 사용한 경우로, 여기서는 원형기반 커 널 함수의 $\sigma$ 를 추정하기 위하여 교차타당성을 통해 주어진 데이터에 적합한 값을 계산하였다. 만약 서 포트 벡터가 되는 관측치가 빠지는 경우, 데이터의 경계는 줄어들게 되고, 제외된 관측치는 이상상태로 판정된다. 다시 말해 제외된 관측치 외의 나머지 데이터는 경계안에 있게 되기 때문에 이때 생길 수 있 는 제 1 종의 오류의 크기는 서포트 벡터의 비율이 된다. Figure 3.4 는 $\sigma$ 의 값에 따라 데이터를 5 번 재표 집하여 구한 서포트 벡터의 비율을 나타낸 것이데, 이를 통해 서포트 벡터의 비율이 가장 작을 때는 $\sigma$ 가 14 인 것을 확인하였다. 


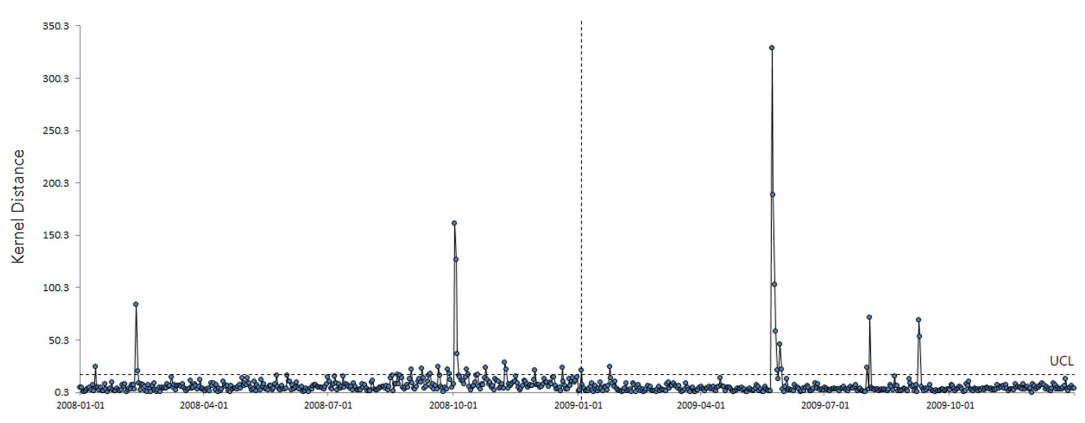

Figure 3.3. K-Chart using Polynomial kernel function

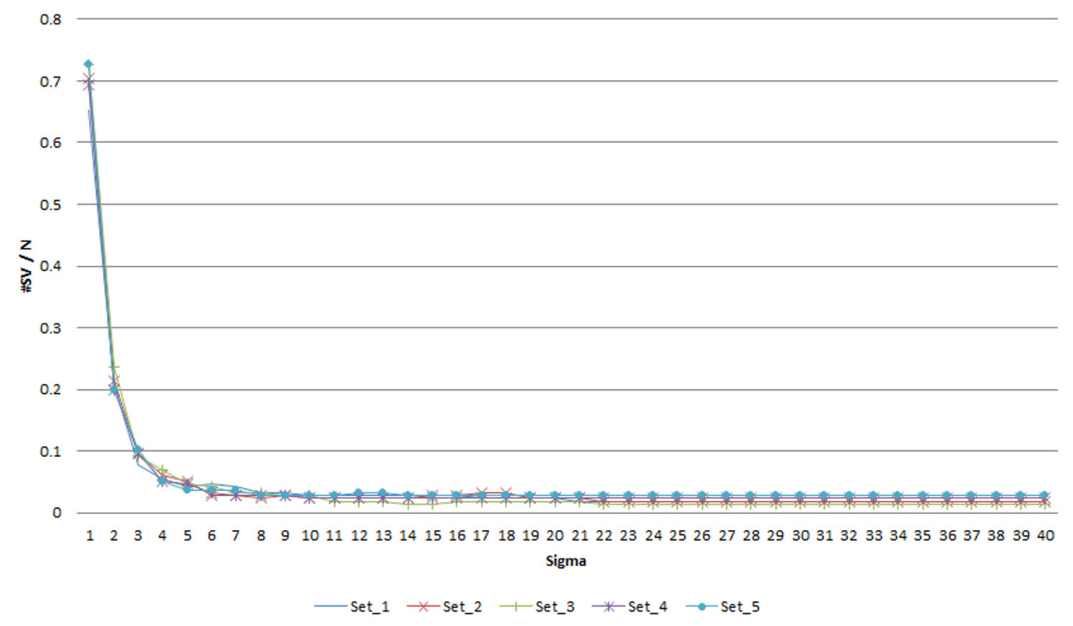

Figure 3.4. Faction of support vectors with respect to the parameter $\sigma$ for 5 resampled samples

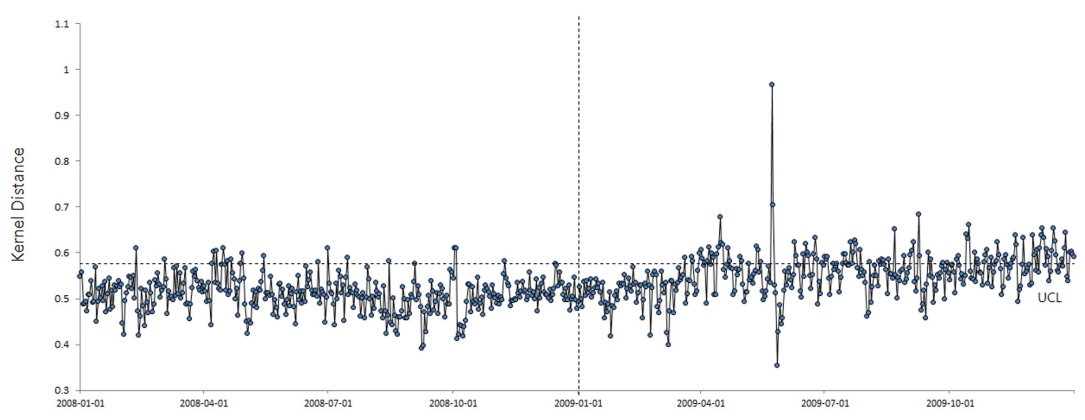

Figure 3.5. K-Chart using RBF kernel function

Figure 3.5 는 $\hat{\sigma}=14$ 로 하여 원형기반함수를 사용한 $\mathrm{K}$-관리도를 나타낸다. K-관리도를 적용한 결과, 관리 상한선은 0.5758 로 나타났으며, 다른 $\mathrm{K}$-관리도와는 다르게 2008년과 2009년에 관리 상한선을 넘 는 날이 자주 발생한 것을 알 수 있었다. 하지만 다른 관리도와 마찬가지로 급격한 이상 상태를 나타내 는 2009년 5월 23일 노무현 전 대통령 서거일은 뚜렷하게 나타났다. Gaussian RBF 커널을 사용하는 
경우에는 $\sigma$ 에 따라 관리도의 형태가 달라지므로 이에 대한 추정에 대하여 추후 연구가 요구된다.

\section{4. 결론 및 향후과제}

본 연구에서는 품질 특성치가 다변량일 경우에 공정관리에서 사용되는 다변량 관리도를 이용하여 소셜 미디어 자료에 적용하여 시간이 흐름에 따라 블로거들의 정서가 변화하는 시점을 탐지해 보았다. 기존 의 다변량 관리도에서 가장 많이 사용되는 관리도는 호텔링 $T^{2}$ 관리도이다. 하지만 호텔링 $T^{2}$ 관리도 는 자료들의 다변량 정규분포 가정이 필요한데 실제 문제에서는 대부분이 정규분포 가정의 적절성을 담 보하기 어렵다. 이러한 문제를 해결하기 위해 Sun과 Tsung (2003)은 단일 클래스 분류의 아이디어를 관리도에 적용한 커널 거리 기반의 관리도인 $\mathrm{K}$-관리도 사용을 제안하였다. 본 연구에서는 실제 다변량 자료로 대표적인 소셜 미디어 자료 중 하나인 블로그 자료로부터 감성어들에 대한 빈도수를 관측하고 이 를 분석 자료로 사용하였다. 최근 SNS의 발달로 블로거들은 사회의 이슈나 사건에 민감하게 자신들의 블로그에 개인적인 생각을 자유롭게 게시하고, 일상의 감정을 블로그에 표현하고 있다. 따라서 이러한 개개인의 감성의 변화를 탐지한다면 사회적으로 불안한 정서를 나타내는 날을 알 수 있다는 가정하에 관 리도를 적용해 보았다. 여기에서는 감성어들 중 부정적으로 표현되는 “힘들다” 외 6 개의 감성어를 분석 에 사용하였는데, 서포트 벡터를 이용한 관리도 분석 결과, 관리 상한선을 넘는 날짜가 사회적으로 좋지 않은 이슈나 사건이 나타난 날들과 일치하는 것을 알 수 있었다. 이러한 분석 결과는 소셜 미디어 자료 에 표현하는 사용자들의 부정적인 감성어들을 통하여 사회 정서를 관측해볼 수 있음을 나타낸다. 향후 에 이 연구를 좀 더 발전시켜서 사회 정서에 대한 모니터링 기법으로 활용가능 할 수 있겠다. 이밖에 기 법면에서도 많은 후속 연구가 필요한데, 예를 들면 이번 자료분석에서는 초구면의 반지름을 선택할 때 $95 \%$ 분위수를 사용했는데, 실제 정상자료에 이상점의 가능성을 허용하고 관리도를 좀 더 로버스트 하기 위해서 모든 관측치로부터 데이터 중심까지의 거리가 초구면의 반지름보다 작다는 가정(식 (2.1)과 식 (2.5)) 대신에 관측치로부터 데이터 중심까지의 거리가 큰 경우에 벌점을 주는 형식으로 서포트 벡터를 추정할 수 있는 등 서포트 벡터기법의 방법을 확대 적용해볼 수 있을 것이다. 또한 $\mathrm{K}$-관리도에서 $\mathrm{RBF}$ 커널 함수 적용 시 $\sigma$ 에 관한 추정은 교차타당성(cross validation)을 통해 결정하는 것이 일반적인데, 작 은 $\sigma$ 는 자료에 대한 경계가 엄격해 그 경계가 데이터의 흩어진 모양만을 따라 나타나며, 큰 $\sigma$ 에 대해서 는 자료에 대한 경계가 SVDD와 마찬가지로 초구면에 가까이 가게 된다. 이러한 $\sigma$ 의 선택은 제 1 종 오 류에 영향을 주어 관리도 성능에 영향을 많이 끼치게 되기 때문에 최적의 $\sigma$ 에 대한 연구가 좀 더 필요하 겠다.

\section{Acknowledgements}

본 논문의 데이터를 얻도록 도움주신 (주)다음소프트 송길영 부사장님께 깊은 감사를 드립니다.

\section{References}

Chiang, L. H., Russell, E. L. and Braatz, R. D. (2001). Fault Detection and Diagnosis in Industrial Systems, Springer, New York.

Crosier, R. B. (1988). Multivariate generalizations of cumulative sum quality-control schemes, Technometrics, 30, 291-303.

Gani, W., Taleb, H. and Limam, M. (2011). An assessment of the kernel distance-based multivariate control chart through an industrial application, Quality and Reliability Engineering International, 27, 391-401.

Hong, J. H. (2011). The detection of public opinion and public opinion cycle via aggregated twitter opinion and sentiment, Korean Journal of Communication Studies, 19, 5-29. 
Hotelling, H. (1931). The generalization of sutdent's ratio, The Annals of Mathematical Statistics, 2, 360378.

Kramer, A. D. I. (2010). An unobtrusive behavioral model of "gross national happiness", Proceeding of the 28th International Conference on Human Factors in Computing Systems, New York, 287-290.

Lowry, C. A., Woodall, W. H., Cahmp, C. W. and Riddon, S. E. (1992). A multivariate exponentially weighted moving average control chart, Journal of Quality Technology, 34, 46-53.

Montgomery, D. C. (2001). Introduction to Statistical Quality Control, John Wiley \& Sons, USA.

Oh, K. S. (2010). A study on the strategic approach to m-Government in the age of social media, Social Science Studies, 34, 135-161.

Prabhu, S. S. and Runger, G. C. (1997). Designing a multivariate EWMA control chart, Journal of Quality Technology, 29, 8-15.

Shewhart, W. A. (1931). Economic control of 1uality of Mmnufactured product, Republished in 1980 by the American Society for Quality Control, D. Van Nostrand Company, Inc., New York.

Sukchotrat, T., Kim, S. B. and Tsung, F. (2010). One-class classification-based control charts for multivariate process monitoring, IIE Transactions, 42, 107-120.

Sun, R. and Tsung, F. (2003). A kernel-distance-based multivariate control charts using support vector methods, International Journal of Production Research, 41, 2975-2989.

Tax, D. and Duin, R. (2004). Support vector data description, Machine Learning, 54, 45-66. 


\title{
다변량 관리도를 활용한 블로거 정서 변화 탐지
}

\author{
문정훈 $^{a} \cdot$ 이성임 ${ }^{b, 1}$ \\ ${ }^{a}$ 이랜드 시스템즈, 정보전략실, 빅어낼러틱스팀; ${ }^{b}$ 단국대학교 응용통계학과
}

(2013년 7월 17일 접수, 2013년 9월 6일 수정, 2013년 10월 29일 채택)

\section{요약}

최근 소셜 네크워크 서비스의 발달로 인해 개인의 감정이나 의견을 표현하는 소셜 데이터들이 하루에도 수백만 건 씩 생산되고 있다. 또한 소셜 데이터는 개인의 의견에 또 다른 생각을 더하는 등 정보의 생산과 소비가 누구나 가 능해짐으로써 사회현상을 잘 반영해주는 도구로 성장하고 있다. 본 연구에서는 블로그에 올라온 부정적인 감성어들 을 분석하여 블로거의 감성변화를 탐지하기 위해 다변량 관리도를 이용하고자 한다. 이를 위해 2008 년 1 월 1 일부터 2009년 12월 31일 사이에 생성되었던 모든 블로그를 사용하였다. 품질 특성치가 다변량으로 주어지는 경우 호텔링 의 $T^{2}$ 관리도가 널리 사용된다. 그러나 이 관리도는 품질 특성치들의 분포가 다변량 정규분포라는 가정을 하고 있 어, 비정규 다변량 자료에 대한 관리도의 성능은 좋지 않다. 이에 본 논문에서는 Sun과 Tsung (2003)이 제안한 써 포트 벡터머신에서 단일 집합 분류 기법 중 하나인 $\mathrm{SVDD}$ (support vector data description) 알고리즘과 이를 확 장한 $\mathrm{K}$-관리도를 소개하고, 실제 데이터 분석에 적용해 보았다.

주요용어: 다변량 관리도, 서포트 벡터 데이터 표현, $\mathrm{K}$-관리도.

이 논문은 2011년도 정부(교육과학기술부)의 재원으로 한국연구재단의 지원을 받아 수행된 기초연구사업임(No. 2011-0025168).

1 교신저자: (448-701) 경기도 용인시 수지구 죽전로 152 , 단국대학교 응용통계학과, 조교수.

E-mail: silee@dankook.ac.kr 